\title{
Escândalos e voto: as eleições presidenciais brasileiras de $2006^{1}$
}

\author{
Lucio R. Rennó \\ Universidade de Brasília
}

\begin{abstract}
Resumo
O artigo mostra o impacto dos escândalos de corrupção sobre o voto do eleitor brasileiro na eleição presidencial de 2006. A pergunta central é se aqueles que consideraram a corrupção como principal problema deixaram de votar em Lula. O artigo avalia se e como os componentes retrospectivo, ideológico e partidário influem no voto bem como o impacto de fenômenos circunstanciais sobre ele. Os dados mostram que as percepções sobre a corrupção têm um peso maior na escolha de candidatos de partidos políticos vizinhos no espectro ideológico brasileiro e peso menor na escolha de candidatos de coalizões partidárias muito distantes neste espectro. Assim, na escolha de voto entre Lula e Alckmin, fatores como percepções sobre a economia, avaliação do governo Lula e certo componente partidário foram mais importantes e serviram de escudos para proteger Lula das acusações de corrupção no cenário da reeleição.
\end{abstract}

Palavras-chave: corrupção; voto retrospectivo; contabilidade democrática; eleição presidencial de 2006.

\begin{abstract}
The article shows the impact of corruption scandals on the Brazilian voter's choice in the 2006 Presidential election and it analyses if those individuals who have considered corruption the main Brazilian problem also did not vote for Lula. The article evaluates if and how the retrospective, ideological and partisan elements have influence on voting, as well as the circumstantial phenomena. Data shows that perceptions about corruption have more impact on the choice for candidates of political parties ideologically neighbors and have less impact on the choice for candidates of ideologically distant political parties. Therefore, the voter's perceptions about economy, the Lula's government performance and some partisan aspect were more important for the choice for President and have protected the candidate from the corruption's accusations.
\end{abstract}

Key-words: Corruption; retrospective voting; democratic accountability; 2006 Presidential election

\footnotetext{
1 Agradeço à Rachel Meneguello e à Ipsos-Opinião pelo acesso aos dados. Agradeço também a David Samuels pela leitura atenta de uma versão preliminar e pelos excelentes comentários. Por último, sou grato aos comentários e sugestões do parecerista anônimo da Revista Opinião Pública. Os erros restantes são de minha responsabilidade.
} 
RENNÓ, L. R. Escândalos e voto: as eleições presidenciais brasileiras de 2006.

Introdução

Corrupção e escândalos afins foram temas centrais das eleições de 2006. Dados de opinião pública, apontados pelo Estudo Eleitoral Brasileiro (ESEB), deixam claro: $30 \%$ dos eleitores brasileiros indicaram a corrupção e escândalos decorrentes como o principal tema da campanha. Em um distante segundo lugar, com $10 \%$, ficaram questões sobre a economia. Portanto, não há como entender o processo eleitoral de 2006 sem falar do impacto dos escândalos de corrupção e de atos ilegais sobre o voto.

Ao relembrarmos o período eleitoral de 2006, um evento marcante que logo vem à mente é a compra de dossiês sobre candidatos adversários envolvendo petistas "aloprados", para utilizar as próprias palavras do presidente Luiz Inácio Lula da Silva. É provável que a ocorrência do segundo turno tenha sido uma conseqüência direta de mais esse escândalo que envolveu diretamente o presidente do Partido dos Trabalhadores (PT), Ricardo Berzoini, e o candidato do PT ao governo de São Paulo, Aloísio Mercadante. Na verdade, se desagregarmos as respostas relacionadas à centralidade da corrupção e escândalos nas eleições, $7 \%$ dos entrevistados indicaram exclusivamente o escândalo do dossiê como o principal tema da eleição de $2006^{2}$.

Além da centralidade como tema de campanha, a corrupção foi também classificada por $42 \%$ dos eleitores como o pior problema político do país e por $8 \%$ como o segundo pior problema. Assim, para a metade do eleitorado brasileiro, a corrupção é um dos principais desafios a ser superado no Brasil hoje. Comparando com os $2 \%$ que apontaram a corrupção como o pior problema do país em 2002, atestado pela rodada de então do ESEB, fica claro que esse problema, antes quase inexistente na visão do eleitor, reforça o argumento de que o traço marcante das eleições de 2006 foi a discussão sobre corrupção (RENNÓ, 2006) ${ }^{3}$.

\footnotetext{
${ }^{2}$ A construção da categoria corrupção dentre os principais temas da eleição foi composta por uma série de resposta à pergunta sobre qual o principal assunto da eleição. A menção a dossiês na campanha está entre elas, assim como as respostas "corrupção", "falta de ética na política", "políticos corruptos", "máfia dos políticos", "combate à corrupção-lavagem de dinheiro", "escândalos envolvendo o governo", "Lula dizer que não sabe dos escândalos" e "lula roubando-difamação de lula" .

${ }^{3}$ Cabe aqui uma ressalva. Há algumas diferenças entre os enunciados das perguntas e os questionários do ESEB 2002 e 2006. Por exemplo, a pergunta sobre o pior problema do país em 2002 estabelece como referencial temporal para a avaliação do entrevistado os últimos quatro anos. O enunciado da pergunta em 2006 enquadra a questão como o pior problema político no último ano. Ou seja, o enfoque das perguntas é bastante distinto, dificultando a comparação. Ainda assim, há uma equivalência funcional entre as duas questões, destacando qual problema é o mais visível para a população. Por isso, a comparabilidade não é totalmente comprometida. Contudo, o problema tampouco pode ser ignorado e por isso é explicitado aqui. Em 2002, também as distintas respostas já foram codificadas na versão final do banco de dados gerando uma categoria para corrupção. Em 2006, as respostas incluídas na formação da variável sobre corrupção são: "falta de ética", "falta de punição para políticos corruptos", "lula dizer
} 
Obviamente que o Escândalo do Dossiê não foi o único levado em consideração. Os dois anos anteriores à eleição foram marcados por escândalos sucessivos de desvios de recursos públicos, compra de apoio de parlamentares através do uso de sobras de campanha e propinas, envolvendo diretamente a cúpula petista do Palácio do Planalto e, em diversos momentos, resvalando no presidente Lula. Primeiro, foi o caso Waldomiro Diniz, figura central dentro da Casa Civil e da articulação entre os Poderes Executivo e Legislativo. Em seguida, surgiram as denúncias contra Roberto Jefferson e seus nomeados na empresa dos Correios, resultando primeiro no escândalo dos Correios e, em seguida, no mega-escândalo que ficou conhecido como Mensalão, envolvendo a compra de apoio legislativo de aliados na Câmara dos Deputados. Todos esses escândalos atingiram em cheio o Chefe da Casa Civil e homem-forte do governo Lula, José Dirceu, resultando em sua queda da posição no Poder Executivo e cassação de seu mandato de deputado federal. Por fim, na ante-véspera da eleição, apareceram as denúncias de super-faturamento de ambulâncias em um esquema de alocação de emendas orçamentárias individuais de deputados federais. Este último evento recebeu o sugestivo nome de Sanguessugas. É possível que o escândalo do Dossiê tenha apenas reavivado na memória do eleitor as constantes acusações de corrupção vividas pelo primeiro mandato de Lula e não foi por acaso que o tema central das eleições foi a corrupção.

A corrupção foi também o tema explorado por todos os candidatos da oposição, que mencionaram em suas campanhas, com maior ou menor intensidade, as graves acusações contra a administração petista.

Em um cenário como esse, o grande enigma das eleições de 2006 foi como um presidente candidato à reeleição, cuja administração se viu envolta em diversos escândalos, e que foi extensivamente atacado por seus adversários, foi reeleito com certa tranqüilidade e quase no primeiro turno (RENNÓ, 2006). Dada a centralidade do tema nas eleições de 2006, o objetivo deste artigo é exatamente propor uma solução para esse enigma e mensurar o impacto dos escândalos de corrupção sobre o voto do eleitor brasileiro. A pergunta central é se os eleitores que consideraram a corrupção como o principal problema do país votaram de forma preponderante em algum candidato ou contra algum candidato. Mais precisamente, e tendo em vista as constantes acusações aos membros do governo, a questão explorada é se aqueles que consideraram a corrupção como principal problema deixaram de votar em Lula. Da mesma forma, avaliamos se os fatores clássicos em estudos eleitorais, como preferência partidária, ideologia e avaliação da economia serviram como "escudo" 4 para o presidente Lula contra acusações de corrupção.

que não sabe da corrupção", "Iula roubando-difamação de lula", "falta de honestidade", "falta de vergonha dos políticos", "compra de dossiês" e "políticos-máfia dos políticos".

4 O termo escudo é influenciado, mesmo que de forma tangencial, pela idéia de "legislative shield" proposta por Peréz-Liñan (2007), definida com base em como a bancada legislativa de um presidente 
RENNÓ, L. R. Escândalos e voto: as eleições presidenciais brasileiras de 2006.

A avaliação do impacto da corrupção sobre o voto é importante também para uma discussão teórica mais ampla sobre contabilidade democrática (accountability), no que tange à capacidade do eleitor de punir seus representantes (PRZEWORSKI et al, 1999). A contabilidade democrática tem, desse modo, um forte componente de voto retrospectivo, de avaliação da atuação passada dos políticos no cargo eletivo, enfocando o desempenho no gerenciamento da economia (STOKES, 2001; RENNÓ e SPANAKOS, 2006). Para alguns, esse pode ser entendido como o voto mais comum e típico de um regime democrático (CONVERSE, 1966; STOKES, 2001).

Mas, o voto retrospectivo tem múltiplas dimensões, pode ser inspirado ou enquadrado (framed) por distintos eventos e temas e envolve diferentes atributos e fatores que vão além do tradicionalmente estudado, a dimensão do desempenho econômico. Pode estar relacionado ao desempenho do governante em outras esferas de atuação, como a probidade administrativa e a lisura.

Portanto, avaliar o impacto da corrupção ao lado de outras explicações sobre o voto promove uma visão mais clara sobre quais critérios de análise retrospectiva os eleitores empregam em sua escolha eleitoral. A própria idéia de "escudo" diz respeito às características das preferências e enfoques dos eleitores que podem levá-los a dar menor importância à corrupção no momento de decisão do voto frente a outras dimensões do voto retrospectivo. Pode ser que a avaliação da economia, também retrospectiva, seja mais importante e se sobreponha à questão da corrupção. Há, ainda, outros fatores que, embora não sejam puramente retrospectivos, podem atenuar o impacto da corrupção, como identificação partidária e ideologia.

$\mathrm{Na}$ seção seguinte, realizamos a discussão teórica sobre contabilidade democrática e derivamos as hipóteses empiricamente verificáveis levando em consideração as particularidades do caso brasileiro. A seção, portanto, combina teoria e empiria na derivação das hipóteses testadas. Em seguida, apresentamos a base de dados e as variáveis que operacionalizam os principais conceitos e hipóteses discutidas. A análise dos dados indica que a corrupção foi um fator importante nas decisões de voto do eleitor brasileiro em 2006. Contudo, o impacto da percepção sobre a corrupção não foi uniforme: afetou algumas escolhas de candidato a presidente e outras não. Esse achado pode esclarecer o enigma da reeleição de Lula, a despeito dos escândalos de corrupção. Por fim, são discutidas algumas implicações teóricas e normativas com base nos achados.

Um cuidado acerca das implicações de nossa análise é que estamos lidando com a percepção dos eleitores sobre escândalos de corrupção baseados em acusações e divulgados pelos meios de comunicação e redes pessoais de conversa

pode evitar impeachments. A argumentação aqui é similar, pois indica quais preferências individuais dos eleitores e a popularidade do presidente podem reduzir a influência de escândalos na esfera política e evitar punições eleitorais. 
política e não sobre casos concretos, julgados e condenados, de corrupção. Essa diferença é importante já que a percepção sobre corrupção não indica, necessariamente, culpa dos envolvidos. Políticos podem utilizar essa retórica para se defender, alegando inocência e perseguição, o que é plenamente aceitável em qualquer regime. Isso também ajuda a entender por que certos eleitores não atribuem tanto peso à corrupção em suas escolhas eleitorais.

\section{Contabilidade Vertical e Cálculos Eleitorais Múltiplos no Brasil}

O conceito de "contabilidade democrática" (PRZEWORSKI et al, 1999) também está na essência da idéia de "contabilidade vertical" proposta por O’Donnell (1994). Em sua discussão sobre democracia delegativa na América Latina, O’Donnell aponta que os eleitores dão carta branca a seus representantes no período entre eleições, acompanhando de longe o processo decisório, de forma a fazer "vista-grossa" à sua atuação. Assim, a capacidade de monitoramento e punição do eleitor sobre o representante que frustra os elos de representação é baixa e o controle sobre o eleito só existiria no momento da eleição, quando o eleitor avalia a atuação do representante e decide seu apoio com base em eventos circunstanciais e pessoais dos candidatos. No caso da democracia delegativa, a possibilidade de "contabilidade vertical", de prestação de contas entre eleitor e eleito, estaria prejudicada em grande parte da América Latina. Conjugada a uma fragilidade de mecanismos de controle horizontal, do poder legislativo sobre o executivo, resultaria em governos com muita amplitude para decisões unilaterais e arbitrárias. Em suma, a democracia delegativa diz respeito, portanto, à ausência de contabilidade democrática vertical e horizontal. Isso ocorreu nas eleições brasileiras de 2006? Uma das grandes questões das eleições de 2006 é como um candidato à reeleição, com sua administração mergulhada em escândalos de corrupção, saiu vitorioso (RENNÓ, 2006). Isso é sinal de ausência de contabilidade vertical?

A partir de Przeworski et al (1999) e O’Donnell (1994), fica claro que o componente retrospectivo é muito importante para a "contabilidade vertical" e, para entendermos como os eleitores controlam e julgam seus representantes, precisamos saber quais critérios empregam na hora do voto. A pergunta, então, é qual foi a influência de elementos retrospectivos no voto para presidente em 2006 ? Torna-se importante desvendar quais são os fatores que influenciam o voto, a fim de identificar os micro-fundamentos da contabilidade eleitoral. Neste caso, é importante avaliar se percepções sobre a corrupção impactaram as escolhas eleitorais em 2006 ou não e, caso haja algum impacto, podemos argumentar que os eleitores não estão alheios ao tema. 
RENNÓ, L. R. Escândalos e voto: as eleições presidenciais brasileiras de 2006.

\section{A) Multidimensionalidade do Voto Retrospectivo}

Fiorina (1981) e Kinder \& Kiewit (1981) nos dão pistas sobre possíveis critérios retrospectivos utilizados por eleitores. Nessa visão, prevalece a idéia de que o estado da economia é fundamental para compreender as avaliações sobre candidatos e suas escolhas eleitorais. As visões sobre a economia, por sua vez, podem estar relacionadas a melhoras ou pioras na vida pessoal do eleitor ou no estado da economia nacional como um todo. Portanto, se a economia vai bem ou se a situação econômica pessoal do eleitor melhora, o candidato à reeleição tem maiores chances de vitória. Essa explicação tem quase status de lei dentro da discussão sobre comportamento eleitoral. No voto retrospectivo econômico, a ênfase está na eficiência da administração no gerenciamento da economia. Mas, ética e honestidade no exercício do mandato também podem ser um critério importante, passando a ser mais um componente do cálculo eleitoral retrospectivo. Escândalos com alegações de corrupção sucessivos podem macular estas dimensões da avaliação retrospectiva. No caso, ganham um caráter sistemático da avaliação do desempenho dos representantes eleitos, e não apenas algo circunstancial da campanha eleitoral.

Um governo marcado por sucessivos escândalos de corrupção pode ser avaliado com base nesse fator mais fortemente do que com base em outros componentes retrospectivos, como a sua eficiência econômica. Mesmo que não haja comprovação da existência de corrupção, a mera veiculação massiva de evidências e os desdobramentos políticos dos eventos, como demissão de membros do governo, audiências públicas em Comissões de Inquérito, entre outros, podem macular dramaticamente a imagem dos políticos envolvidos. Além disso, os adversários dos envolvidos em escândalos buscam capitalizar politicamente eventos, evitando que o tema saia da agenda pública e procurando sempre aumentar sua saliência.

Em suma, mesmo quando se fala apenas de voto retrospectivo, é possível apontar a multidimensionalidade desse padrão de decisão eleitoral, enfocando distintos aspectos do desempenho de políticos no cargo, como eficiência, honestidade, solidariedade social, entre outros. A multimensionalidade do voto retrospectivo é algo ainda pouco explorado na literatura sobre comportamento eleitoral. 


\section{B) Cálculos Eleitorais Múltiplos}

Mas, o voto retrospectivo não é o único modo de cálculo eleitoral. Susan Stokes (2001) aponta outras formas de escolha. Os eleitores podem utilizar, além do voto retrospectivo, componentes mais prospectivos, como um cálculo intertemporal, no qual custos e dificuldades econômicas são aceitas no curto prazo para que haja bonança no futuro. No caso, o estado da economia continua a ser importante, mas melhoras na economia não necessariamente têm um efeito positivo sobre as chances de reeleição do presidente, pois podem indicar políticas irresponsáveis com o longo prazo.

Há também o voto ideológico, que se baseia nas preferências de longo prazo do eleitor e sua vinculação a partidos políticos. Os eleitores apóiam candidatos de seus partidos ou próximos ideologicamente independente do desempenho desses candidatos no exercício do mandato. Em um caso extremo, avaliações sobre o estado da economia e sobre o desempenho dos políticos no poder podem não ter qualquer influência sobre o voto. As questões ideológica e partidária podem atenuar o impacto de elementos circunstanciais ou de avaliações do desempenho dos políticos.

$\mathrm{Na}$ literatura, o voto ideológico ou partidário é entendido como uma explicação de longo prazo para o voto, em oposição a fatores de curto prazo, mais relacionados com eventos da campanha (HOLBROOK, 1994; GREEN e PALMQUIST, 1994). Claro, Stokes não foi a primeira a chamar a atenção para o impacto das lealdades de longo prazo na escolha eleitoral. O estudo clássico sobre decisão eleitoral, The American Voter, de Cambell et al (1960), já chamava a atenção para o papel dos partidos políticos na definição da escolha de candidato. Pappi (1996), mais recentemente, apontou para o papel da ideologia na escolha do voto em sistemas multipartidários. Outros atalhos cognitivos também foram identificados, como os sinais emitidos por grupos de apoiadores de um candidato (endorsers) (SNIDERMAN, 2000).

É interessante notar que, no estudo clássico de Campbell et al (1960), o voto partidário, de longo prazo, era visto como uma explicação residual para a escolha eleitoral. Os eleitores americanos não votariam baseados em issues, em temas de campanha, mas, sim, de acordo com preferências cristalizadas no longo prazo e, até certo ponto, sem muito raciocínio ou espírito crítico. Para esta visão, o voto baseado só no partido não é uma alternativa interessante se ela serve para mascarar atuações duvidosas dos representantes eleitos. Assim, o voto partidário, sem embasamento em preferências temáticas ou baseado em políticas públicas frágeis, pode resultar em escolhas pouco informadas. 
RENNÓ, L. R. Escândalos e voto: as eleições presidenciais brasileiras de 2006.

Green e Palmquist (1994) vão na mesma linha, afirmando que a identificação partidária e a preferência ideológica são componentes de uma lealdade de mais longo prazo, fatores considerados imunes às pressões e dinâmicas particulares de campanhas eleitorais. Tais eventos de campanha, acontecimentos circunstanciais que caracterizam um episódio eleitoral, são entendidos como de curto prazo. Incluem-se aí participação em debates e estilos de propaganda eleitoral (HOLBROOK,1994). Escândalos circunstanciais, como o do Dossiê, entra também nessa categoria. No entanto, como foi argumentado antes, quando escândalos de corrupção passam a ser uma constante em uma administração, não estando limitados apenas ao período de campanha, então, podem ser vistos como um componente mais sistemático, afetando o voto retrospectivo, e não apenas circunstâncias, de curto prazo. Em outras palavras, se uma administração passa a ser associada à corrupção e a escândalos, esse fator passa a ser caracterizador de seu desempenho passado e critério para o voto retrospectivo. Esse parece ser o caso do primeiro mandato do governo Lula.

Com base nesta discussão, fica claro que há uma multiplicidade de fatores que podem influenciar o voto: os votos restrospectivo, ideológico e partidário; e há, ainda, o impacto de fenômenos circunstanciais. A avaliação da economia não é a única forma de análise retrospectiva do desempenho do governo, há outras dimensões da atuação de políticos no cargo que podem e são empregadas pelo eleitor no momento da decisão do voto. Resta ver como esse fatores influenciaram as escolhas eleitorais no Brasil.

\section{C) O Caso Brasileiro - Ambivalência entre Cálculos Múltiplos}

No caso das eleições brasileiras de 2006, há indícios de que o voto retrospectivo não se baseou apenas na avaliação da economia. Este pode ter sido um dos possíveis critérios, mas não o único. Visões sobre honestidade e probidade administrativa podem ter sido também um fator retrospectivo que afetou decisões de voto. Nessa perspectiva, o eleitor pode se encontrar em uma situação de ambivalência ao decidir como pesar os distintos atributos do desempenho dos políticos eleitos (FELDMAN e ZALLER, 1992; ZALLER, 1992). Além disso, outros critérios, como preferência ideológica e partidária, que possivelmente têm uma durabilidade maior do que os eventos circunstanciais de uma campanha ou de uma administração, podem complicar ainda mais a situação, gerando um escudo para políticos com desempenho duvidoso.

Para o caso brasileiro, há mais debates inconclusos sobre o impacto de variáveis de longo prazo sobre o voto do que para sistemas políticos onde os partidos políticos existem há mais tempo e estão mais institucionalizados (MAINWARING e SCULLY, 1995). Há autores que encontram alguma relevância do 
peso partidário na decisão de voto no Brasil, principalmente no caso do PT, e quando se inclui na equação não apenas identificação, mas também rejeição partidária (SINGER, 1999; CARREIRÃO e BARBETTA, 2004; CARREIRÃO e KINZO, 2004; CARREIRÃO, 2007; NICOLAU, 2007). Por outro lado, alguns autores questionam a importância dos partidos e da ideologia na escolha eleitoral. Almeida (2001) indica que a maior parte dos eleitores não consegue se posicionar em uma escala de preferência ideológica entre esquerda e direita, o que enfraquece o uso desse indicador para prever escolhas eleitorais. Samuels (2006), por sua vez, indica que a própria identificação partidária é mais bem explicada pela preferência do eleitor acerca das lideranças do partido. Neste caso, a identificação partidária seria explicada pelas características pessoais dos líderes partidários e pelo apego do eleitor às suas personalidades.

Cabe destacar aqui a limitação de dados transversais de opinião pública, coletados em uma amostra em apenas um momento do tempo, para a mensuração adequada do impacto da preferência ideológica e da identificação partidária na escolha eleitoral tanto para o Brasil como para outros locais onde partidos políticos existam há pouco tempo ou estejam atravessando processos de institucionalização (MAINWARING e SCULLY, 1995). Está explícita no uso desses dados a idéia de que a identificação partidária e a preferência ideológica, quando utilizadas para explicar voto, são duráveis, de longo prazo e estáveis no tempo, características básicas de variáveis exógenas em um modelo analítico. Contudo, há evidências de que a identificação partidária não contém nenhuma dessas características no caso brasileiro para uma parcela significativa do eleitorado. Na verdade, Ames et al (2006), usando dados de painel coletados em duas cidades brasileiras nas eleições de 2002 e, posteriormente, em 2004, encontram que há flutuações substantivas da identificação partidária de eleitores quando medida em momentos diferentes da campanha e entre campanhas. Isso coloca em xeque o papel que partidos políticos têm na definição da escolha eleitoral. Contudo, como não temos dados longitudinais para a presente análise, utilizamos os dados de preferência partidária disponíveis na expectativa de que estudos futuros, utilizando dados longitudinais, possam testar essas hipóteses novamente.

Não obstante, é importante modelar o impacto da identificação partidária junto ao eleitorado. É plenamente razoável supor que a identificação partidária e a preferência ideológica podem atenuar o impacto da corrupção quando se tratar da escolha entre candidatos de partidos políticos distantes no espectro ideológico. Em outras palavras, quando a diferença ideológica e partidária é grande, valores circunstanciais ou retrospectivos terão menor força. É importante, também, testar essa hipótese ao lado de outras explicações tradicionais do voto no Brasil, como visões sobre a economia e outros controles, como gênero, idade e escolaridade (MENEGUELLO, 1994; RENNÓ e SPANAKOS, 2006; CARREIRÃO, 2007; NICOLAU, 
RENNÓ, L. R. Escândalos e voto: as eleições presidenciais brasileiras de 2006.

2007). Outra ressalva importante é necessária: algumas explicações clássicas do voto no Brasil, como visões sobre as características pessoais de candidatos ou temas específicos da campanha não estão disponíveis no ESEB 2006 e não poderão ser incluídas no modelo (CARREIRÃO, 2002; 2006).

Assim, com base na discussão sobre a multidimensionalidade do voto retrospectivo e sobre a idéia de que lealdades de longo prazo podem atenuar visões mais críticas acerca do desempenho de candidatos distintos no espectro ideológico, levantamos as seguintes hipóteses para analisar a eleição de 2006:

Hipótese 1: As percepções sobre corrupção deverão ter impacto negativo sobre o voto em Luiz Inácio Lula da Silva, principalmente quando o eleitor estiver decidindo entre candidatos que estão do mesmo lado do espectro ideológico. Portanto, as visões sobre a corrupção terão um peso maior na escolha entre candidatos de partidos políticos próximos no espectro ideológico - como Lula e Cristóvam Buarque e Lula e Heloísa Helena - e menor na escolha entre candidatos de coalizões partidárias muito distantes no espectro ideológico brasileiro - como entre Lula e Alckmin, este pertencente a uma coalizão claramente à direita.

Hipótese 2: Nesse sentido, a identificação partidária, a posição ideológica dos partidos e a avaliação do governo Lula, uma forma mais geral de voto retrospectivo, servirão de escudos contra os efeitos negativos causados pelos escândalos de corrupção envolvendo a administração do candidato à reeleição.

\section{Dados e Variáveis}

Utilizamos as bases de dados do ESEB 2002 e 20065. Os dados de 2002 foram utilizados apenas para a comparação feita anteriormente sobre a centralidade da corrupção nas eleições. As análises a seguir baseiam-se exclusivamente nos dados de 2006, que contêm mensurações sobre intenção de voto para todos os cargos, alguns indicadores de informação política, de identificação e rejeição partidária, de preferência ideológica assim como avaliações sobre os principais problemas do país.

$\mathrm{Na}$ análise, a variável dependente é uma variável nominal que indica o voto no primeiro e segundo turnos da eleição de 2006; portanto, são analisadas, no primeiro turno as escolhas entre os candidatos Luiz Inácio Lula da Silva, Geraldo

${ }^{5}$ O ESEB 2002 é representativo nacionalmente e conta com uma amostra de 2513 casos coletados entre 31 de outubro e 28 de dezembro de 2002. O ESEB 2006 foi coletado pelo CESOP e pela IPSOS -Opinion entre 17 e 27 de dezembro de 2006 e com uma amostra nacional representativa de 1000 casos sorteados aleatoriamente em 70 municípios brasileiros. 
Alckmin, Cristóvam Buarque, Heloísa Helena e o não-voto, que inclui abstenção, voto em branco e nulo. No segundo turno, as opções foram Lula e Alckmin e o nãovoto. As escolhas de outros candidatos, com votações inexpressivas, foram omitidas $^{6}$.

As variáveis independentes são:

1) Percepções sobre corrupção como principal problema nacional indicadas por afirmações em questão aberta sobre o principal problema político do país. As respostas relacionadas com corrupção receberam valor 1 . As demais receberam valor 0 . Foram somadas as respostas para a corrupção como principal problema e como segundo mais importante. Portanto, o valor último da variável é 0,1 e 2, com o valor 2 significando que a corrupção é o principal problema e o valor 1 indicando que a corrupção é o segundo principal problema. Portanto, é uma variável que indica o grau crescente de importância para o eleitor da corrupção como problema nacional. Essa variável deverá ter um impacto negativo sobre o voto em Lula, principalmente quando comparado com outros candidatos de esquerda.

2) Percepções sobre a economia, indicadas por afirmações em questão aberta sobre o principal problema do país. As respostas relacionadas às questões econômicas receberam valor 1 . As demais receberam valor 0 . Foram somadas as respostas para a economia como principal problema e como segundo mais importante. Novamente, portanto, o valor último da variável é 0,1 e 2, com o valor 2 significando que a economia é o principal problema e o valor 1 indicando que a economia é o segundo principal problema. Assim como para a variável anterior, trata-se de um indicador de grau crescente de importância para o eleitor da economia como problema nacional. Essa variável deverá ter impacto negativo sobre o voto em Lula, principalmente quando comparado a Alckmin. Quem acredita que temas econômicos são o principal problema político do país irá votar contra a administração petista, principalmente em seu principal adversário. Cabe destacar que a economia, nessa operacionalização, é entendida como um fator negativo, por isso deverá afetar negativamente o candidato à reeleição.

3) Avaliação do desempenho do governo Lula, indicada por quatro categorias: ótimo, bom, ruim e péssimo. As duas primeiras opções foram agrupadas e diferenciadas de todas as demais respostas. Assim, foi criada uma variável dummy com valor 1 para avaliações "ótimo" e "bom" e 0 para as demais alternativas. Essa

6 Irei me referir aos candidatos como eles são popularmente conhecidos: Lula, Cristóvam, Alckmin e Heloísa Helena. Foram omitidos os dois votos em Luciano Bivar identificados pelo ESEB 2006. Os candidatos José Maria Eymael, Ana Maria Rangel e Rui Costa Pimenta não receberam votos na amostra analisada. Há 165 casos ausentes na declaração de voto no primeiro turno e 146 no segundo turno. 
RENNÓ, L. R. Escândalos e voto: as eleições presidenciais brasileiras de 2006.

é outra variável clara de voto retrospectivo. Avaliações positivas de Lula deverão aumentar a probabilidade de voto nele.

4) Identificação partidária com o PT, indicada pela declaração do eleitor de que tem alguma simpatia pelo Partido dos Trabalhadores. Recebe valor 1 se gosta do PT e valor 0 todas as demais respostas. Essa variável deverá ter impacto positivo sobre o voto em Lula.

5) Rejeição ao PT, indicada por uma variável que pergunta em que partido não votaria de forma alguma. Recebe valor 1 a menção ao PT e todas as demais respostas recebem o valor 0 . 0 uso dessa variável foi inspirado pelos achados de Carreirão e Barbetta (2004), que indicam que não apenas a identificação partidária, mas também a rejeição ao PT funcionam como uma âncora para as preferências eleitorais dos cidadãos. A expectativa é que quem não gosta do PT não vota em Lula.

6) Preferência ideológica, medida por uma variável com valores entre 0 e 10 , indicando o auto-posicionamento do eleitor em uma escala que vai da esquerda para a direita. Essa medida é problemática por que $41 \%$ da amostra não souberam se posicionar na escala, confirmando achados anteriores de Almeida (2001). Uma medida melhor de ideologia, principalmente na eleição de 2006, seria a posição quanto a um tema divisório no Brasil, como é a questão da privatização. Infelizmente, não há variável que mensure opiniões sobre temas no ESEB de 2006, por isso, foi acrescentada na análise uma variável que indica se o eleitor é de esquerda ou não. A média do posicionamento entre os que se posicionaram na escala esquerda-direita foi 6 , com um desvio padrão de 2 . Como um terço da amostra que respondeu a pergunta se concentra entre valores 0 a 5 , optamos por classificar como de esquerda os eleitores com valor 5 ou menos na escala de resposta. Portanto, classificamos eleitores entre o terço mais à esquerda do eleitorado como de esquerda e os demais, inclusive os que não souberam se posicionar, como não sendo de esquerda. Essa é uma alternativa limitada e imprecisa para tratar a questão ideológica, mas menos idiossincrática do que arbitrariamente definir um valor que indica posição à esquerda. Esses eleitores receberam valor 1 na variável recodificada. Todos os demais, inclusive os que não responderam à pergunta, receberam valor 0 . Obviamente, essa operacionalização não é a ideal e poderá atenuar o impacto da variável, já que está impregnada de erro. O fato de a variável independente conter erro de mensuração reduz sua eficiência e pode resultar em um erro de tipo II, um falso negativo, de aceitar a hipótese nula, quando a mesma deveria ser rejeitada. Contudo, excluir essa variável completamente resultaria em um erro de especificação do modelo, já que essa 
variável é tida como importante para a análise do comportamento eleitoral do brasileiro. Excluir uma variável teoricamente relevante resulta em um erro que gera viés, causando um problema maior do que ineficiência (KING, KEOHANE e VERBA, 1994). Teoricamente, o impacto dessa variável deverá favorecer o voto em Lula em contraste com Alckmin. Para as demais escolhas, é difícil prever.

Uma forma complementar de lidar com a questão ideológica nas eleições de 2006 é distinguir o impacto das distintas explicações para o voto nas diversas escolhas entre candidatos oferecidas aos eleitores. Lula, Cristóvam e Heloísa Helena são de partidos considerados de esquerda, portanto, podemos pensar que a escolha entre esses candidatos seja influenciada por fatores distintos da escolha entre Lula e Alckmin, este último de uma coligação considerada de direita. A questão ideológica seria identificada pela variação no impacto dos determinantes do voto na decisão sobre as diferentes alternativas de escolha. Mais precisamente, visões sobre corrupção podem influenciar escolhas entre candidatos que estão situados no mesmo lado do espectro ideológico, enquanto entre candidatos mais distintos ideologicamente esse fator pode ser secundário.

7) Informação política, medida por um índice que soma respostas corretas a perguntas sobre conhecimento político. Informação política é um fator que pode alterar escolhas eleitorais (LUSKIN, 2002). Contudo, esse índice não mede informação específica sobre cada candidato ou partido, o que é tido como informação política mais relevante (DELLI CARPINI e KEETER, 1996; LUPIA, 1994). Por isso, o efeito dessa variável pode ser fraco, mas, de qualquer forma, é a única opção existente e, para evitar vieses de estimação, será incluída na análise. Essa é mais uma variável de controle do que uma hipótese clara sobre a direção do voto.

8) Controles para nível educacional, sexo e idade. As perguntas utilizadas para a construção destas variáveis estão listadas no apêndice.

\section{Análise e Resultados}

Para a análise da escolha eleitoral no primeiro e no segundo turnos das eleições de 2006 foi utilizado um modelo de regressão multivariada com uma função de ligação multinominal, a fim de contemplar o caráter nominal e de múltiplas categorias das variáveis dependentes (NICOLAU, 2007). Como o vencedor no episódio eleitoral foi o candidato do PT, Lula, sua categoria serviu de referência para comparar o impacto das variáveis nas escolhas eleitorais. Nessa forma de estimação, as demais alternativas de escolha são contrastadas com a categoria de referência simultaneamente, usando o mesmo modelo. Portanto, contrastamos o 
RENNÓ, L. R. Escândalos e voto: as eleições presidenciais brasileiras de 2006.

voto declarado em Lula frente a todas as demais opções. Como o voto declarado em Lula é a categoria de referência, valores negativos nos coeficientes de uma variável indicam aumento da probabilidade de voto em Lula. Valores positivos indicam aumento da probabilidade de voto em cada um dos demais candidatos. A Tabela 1 apresenta os resultados para o primeiro turno das eleições de 2006.

Tabela 1: Regressão Logística Multinominal para Escolha Eleitoral no Primeiro Turno das Eleições de 2006, Brasil.

\begin{tabular}{|c|c|c|c|c|}
\hline & $\begin{array}{c}\text { Lula - } \\
\text { Alckmin }\end{array}$ & $\begin{array}{c}\text { Lula - } \\
\text { Heloísa Helena }\end{array}$ & $\begin{array}{c}\text { Lula - } \\
\text { Cristóvam }\end{array}$ & $\begin{array}{c}\text { Lula - } \\
\text { Não-voto }\end{array}$ \\
\hline Corrupção & $\begin{array}{l}-0.111 \\
(0.75) \\
\end{array}$ & $\begin{array}{l}0.356 \\
(1.47) \\
\end{array}$ & $\begin{array}{c}0.735 \\
(1.93)^{* *} \\
\end{array}$ & $\begin{array}{l}0.439 \\
(0.98) \\
\end{array}$ \\
\hline Economia & $\begin{array}{c}0.366 \\
(2.46)^{* *}\end{array}$ & $\begin{array}{l}-0.087 \\
(0.37) \\
\end{array}$ & $\begin{array}{l}0.250 \\
(0.59) \\
\end{array}$ & $\begin{array}{l}-0.097 \\
(0.21) \\
\end{array}$ \\
\hline $\begin{array}{c}\text { Avaliação Retrospectiva } \\
\text { Governo Lula }\end{array}$ & $\begin{array}{c}-2.516 \\
(9.82)^{* * *}\end{array}$ & $\begin{array}{c}-1.964 \\
(4.95)^{* * *} \\
\end{array}$ & $\begin{array}{c}-1.676 \\
(2.50)^{* *}\end{array}$ & $\begin{array}{c}-2.522 \\
(4.87)^{* * * *} \\
\end{array}$ \\
\hline $\begin{array}{l}\text { Informação } \\
\text { Generalizada }\end{array}$ & $\begin{array}{c}0.290 \\
(2.13)^{* * *}\end{array}$ & $\begin{array}{l}0.006 \\
(0.03) \\
\end{array}$ & $\begin{array}{l}0.253 \\
(0.44) \\
\end{array}$ & $\begin{array}{l}-0.401 \\
(1.58)^{*} \\
\end{array}$ \\
\hline Rejeição ao PT & $\begin{array}{c}1.849 \\
(7.86)^{* * *} \\
\end{array}$ & $\begin{array}{c}1.349 \\
(3.27)^{* * *} \\
\end{array}$ & $\begin{array}{r}0.966 \\
(1.57)^{*} \\
\end{array}$ & $\begin{array}{c}3.231 \\
(4.57)^{* * *} \\
\end{array}$ \\
\hline Simpatia ao PT & $\begin{array}{c}-2.192 \\
(3.59)^{* * *}\end{array}$ & $\begin{array}{l}-0.448 \\
(0.85) \\
\end{array}$ & $\begin{array}{c}-37.775 \\
(76.22)^{* * *}\end{array}$ & $\begin{array}{l}0.230 \\
(0.21) \\
\end{array}$ \\
\hline Esquerda & $\begin{array}{l}0.043 \\
(0.17) \\
\end{array}$ & $\begin{array}{l}0.573 \\
(1.55) \\
\end{array}$ & $\begin{array}{l}0.520 \\
(0.81) \\
\end{array}$ & $\begin{array}{l}0.206 \\
(0.41) \\
\end{array}$ \\
\hline Sexo & $\begin{array}{c}0.460 \\
(1.97)^{* *}\end{array}$ & $\begin{array}{l}0.466 \\
(1.29)\end{array}$ & $\begin{array}{l}0.082 \\
(0.13)\end{array}$ & $\begin{array}{l}0.347 \\
(0.69)\end{array}$ \\
\hline Idade & $\begin{array}{l}0.008 \\
(0.92) \\
\end{array}$ & $\begin{array}{c}0.024 \\
(2.42)^{* *}\end{array}$ & $\begin{array}{l}0.040 \\
(1.29) \\
\end{array}$ & $\begin{array}{l}0.007 \\
(0.36) \\
\end{array}$ \\
\hline Grau de Instrução & $\begin{array}{c}0.247 \\
(4.02)^{* * *}\end{array}$ & $\begin{array}{c}0.259 \\
(3.29)^{* * *}\end{array}$ & $\begin{array}{c}0.591 \\
(2.91)^{* * *}\end{array}$ & $\begin{array}{l}0.161 \\
(1.30)\end{array}$ \\
\hline Constante & $\begin{array}{c}-2.784 \\
(3.75)^{* * *}\end{array}$ & $\begin{array}{c}-4.659 \\
(4.38)^{* * *}\end{array}$ & $\begin{array}{c}-9.095 \\
(3.94)^{* * *}\end{array}$ & $\begin{array}{c}.4 .557 \\
(2.26)^{* *} \\
\end{array}$ \\
\hline Observações & 833 & 833 & 833 & 833 \\
\hline
\end{tabular}

Estatísticas z Robustas em parênteses

* significativo a $10 \%$; ** significativo a $5 \%$; ${ }^{* * *}$ significativo a $1 \%$

Fonte: ESEB, 2006. 
Os dados sobre a escolha no primeiro turno indicam um impacto limitado das avaliações sobre corrupção. Contudo, conforme esperado, percepções sobre corrupção levaram os eleitores a escolher Cristóvam Buarque sobre Lula, ambos de partidos de esquerda. Também o voto em Heloísa Helena foi influenciado positivamente pelas visões sobre corrupção, mas estatisticamente significativo apenas ao nível .15. Ou seja, a hipótese 1 é parcialmente confirmada: o impacto da corrupção afetou apenas escolhas entre candidatos de partidos de esquerda. É interessante notar que as preocupações com questões econômicas, que normalmente são utilizadas como o único indicador de voto retrospectivo, não tiveram qualquer efeito na escolha de voto entre candidatos de partidos de esquerda.

Por outro lado, a percepção sobre a economia afetou a decisão de voto entre Lula e Alckmin, o principal candidato da oposição e representante da coalizão que governou o país antes de Lula. Quando a economia era vista como um problema nacional, a chance de votar em Alckmin aumentava. Já o efeito da corrupção foi inverso ao dos demais candidatos. Quanto maior a visão de que corrupção é um problema, menor a chance de votar em Alckmin, mas o resultado não é estatisticamente significativo. Portanto, visões sobre corrupção não diferenciam a escolha entre Alckmin e Lula no primeiro turno, também conforme previsto na hipótese 1.

Cabe ressaltar que uma variável central para entender a escolha eleitoral feita em 2006 é a avaliação do governo Lula, um indicador mais geral de avaliação retrospectiva (STOKES, 2001). Avaliar positivamente o governo Lula foi decisivo para votar no candidato à reeleição. Cabe destacar que os dados do ESEB 2006 apontam para uma avaliação favorável a Lula entre $75 \%$ dos entrevistados. Dessa forma, não é possível entender a escolha em Lula sem levar em conta a avaliação retrospectiva geral de seu governo.

Com relação às demais variáveis, cabe destacar o efeito das duas formas de avaliar o impacto da preferência partidária na eleição. Como apontaram Carreirão e Barbetta (2004), rejeição ao PT reduz a chance de votar em Lula e a identificação com o PT aumenta essa chance. O impacto da rejeição é claro em todas as escolhas e reduz a probabilidade de votar em Lula, mas não deixa evidente qual candidato se beneficia mais, pois se rejeitar o PT implica em não votar em Lula, não necessariamente implica em votar em outro candidato. Se considerarmos o tamanho dos coeficientes como indicação, embora sua interpretação direta não seja de fácil interpretação, podemos supor que a magnitude maior indica maior força do impacto. Nesse caso, a rejeição ao PT favoreceu mais Alckmin.

Quanto à identificação com o PT, o impacto favorável a Lula só não ocorreu com relação ao voto em Heloísa Helena. Assim, alguns petistas podem ter votado nessa candidata. Por outro lado, houve um forte impacto negativo da identificação com o PT no voto de Cristóvam e Alckmin: aqueles que se declaram petistas não votaram em nenhum desses candidatos. 
RENNÓ, L. R. Escândalos e voto: as eleições presidenciais brasileiras de 2006.

Se analisarmos os efeitos da identificação partidária, avaliações do governo Lula, visões sobre corrupção e economia e da posição ideológica dos partidos dos candidatos, temos uma visão mais completa sobre o processo eleitoral de 2006. Identificação partidária com o PT serviu de escudo para Lula contra as acusações de corrupção quando contrastado com Alckmin. Nesse caso, avaliações da economia passaram a ser mais relevantes. Já quando se tratou de escolhas entre candidatos do mesmo lado do espectro ideológico, e cabe lembrar que Lula, Cristóvam e Heloísa Helena foram correligionários no PT, então corrupção veio à tona como um fator de escolha de um candidato de oposição à esquerda de Lula. Uma variável que teve impacto decisivo em todas as escolhas de voto, ajudando a dizimar ambigüidades, foi a avaliação do governo Lula uma forma de voto retrospectivo geral. Quem gostou do desempenho de Lula, votou em Lula. Ou seja, Lula teve alguns escudos poderosos para se proteger das acusações de corrupção, o que confirma em grande parte a hipótese dois.

Em suma, podemos dizer que a escolha de voto entre Lula e Alckmin no primeiro turno indica padrões claros de voto retrospectivo e foi influenciado pelo posicionamento ideológico dos partidos. Já quando nos voltamos para votos dentro da esfera de partidos de esquerda, as visões sobre corrupção passam a ser influentes. Mas a disputa pela vitória se deu entre Lula e Alckmin e a ausência de impacto da corrupção nessa escolha pode ter sido central para explicar o resultado final do pleito.

Quanto às demais variáveis, cabe indicar que seus efeitos não foram tão relevantes, exceto nível de escolaridade. Auto-posicionamento ideológico não pareceu influenciar o voto, indicando sua alta imprecisão na mensuração. Informação política aumentou apenas as chances de voto em Alckmin. Idade afetou apenas o voto em Heloísa Helena, aumentando seu apoio. Grau de escolaridade também reduziu as chances de voto em Lula, tendo impacto positivo sobre os votos de Alckmin, Cristóvam e Heloísa Helena.

Por fim, a escolha entre votar em Lula, por um lado, ou se abster, votar em branco ou nulo, por outro, foi influenciada pela avaliação do governo Lula, pela rejeição ao PT e por níveis informacionais. Portanto, escolher não votar foi influenciado por avaliações negativas do desempenho de Lula e rejeição ao PT. Não ter votado pode ser visto como um protesto contra o Partido dos Trabalhadores e o governo Lula, principalmente por parte de eleitores com nível informacional mais baixo. Uma possibilidade explicativa para a escolha pelo não-voto é que eleitores que não gostam do PT e do governo Lula não encontraram um candidato que os interessasse ou não tiveram informação suficiente sobre os candidatos para permitir uma escolha. 
OPINIÃO PÚBLICA, Campinas, vol. 13, n², Novembro, 2007, p.260-282

E quanto ao segundo turno? Os padrões de transferência de voto entre candidatos e a campanha eleitoral mudaram os resultados encontrados acima? A Tabela 2 apresenta resultados que replicam em grande parte para o segundo turno o padrão de escolha encontrado entre Lula e Alckmin no primeiro turno da eleição de 2006.

Tabela 2: Regressão Logística Multinominal para Escolha Eleitoral no Segundo Turno das Eleições de 2006, Brasil.

\begin{tabular}{|c|c|c|}
\hline & \\
\hline & $(1)$ & (2) \\
\hline & Lula - Alckmin & Lula - Não Voto \\
\hline \multirow{2}{*}{ Corrupção } & $\cdot 0.244$ & 0.015 \\
\hline & $(1.71) *$ & $(0.08)$ \\
\hline \multirow{2}{*}{ Economia } & 0.418 & 0.307 \\
\hline & $(2.82)^{* *}$ & $(1.56)$ \\
\hline \multirow{2}{*}{ Avaliação Retrospectiva Governo Lula } & .2 .605 & -1.468 \\
\hline & $(10.43)^{* * *}$ & $(4.83)^{* * *}$ \\
\hline \multirow{2}{*}{ Informação Generalizada } & 0.254 & .0 .181 \\
\hline & $(1.96)$ & $(1.14)$ \\
\hline \multirow{2}{*}{ Rejeição ao PT } & 1.817 & 1.577 \\
\hline & $(8.12)^{* *}$ & $(5.32)^{* * *}$ \\
\hline \multirow{2}{*}{ Simpatia ao PT } & $\cdot 2.001$ & -1.007 \\
\hline & $(3.91)^{* *}$ & $(1.96)$ \\
\hline \multirow{2}{*}{ Esquerda } & -0.179 & -0.020 \\
\hline & $(0.73)$ & $(0.07)$ \\
\hline \multirow{2}{*}{ Sexo } & 0.340 & 0.160 \\
\hline & $(1.51)$ & $(0.59)$ \\
\hline \multirow{2}{*}{ Idade } & .0 .002 & -0.021 \\
\hline & $(0.20)$ & $(1.79)$ \\
\hline \multirow{2}{*}{ Grau de Instrução } & 0.215 & .0 .030 \\
\hline & $(3.72)^{* * *}$ & $(0.42)$ \\
\hline \multirow{2}{*}{ Constante } & -1.716 & .0 .635 \\
\hline & $(2.33)^{*}$ & $(0.73)$ \\
\hline Observações & 855 & 855 \\
\hline
\end{tabular}

Estatísticas z Robustas em parênteses

* significativo a $10 \%$; ** significativo a $5 \%$; ${ }^{* * *}$ significativo a $1 \%$

Fonte: ESEB, 2006. 
RENNÓ, L. R. Escândalos e voto: as eleições presidenciais brasileiras de 2006.

Os dados mostram que percepções sobre corrupção foram significativas no segundo turno, mas na direção contrária à esperada: eleitores que identificaram a corrupção como um problema nacional tenderam a votar mais em Lula. Ou seja, o efeito que já era favorável a Lula no primeiro turno, mas não era estatisticamente significativo, no segundo turno passou a sê-lo. Os demais efeitos permaneceram constantes. Por que até aqueles com visões sobre a corrupção como problema principal preferiram Lula sobre Alckmin no segundo turno?

Algumas variáveis descritivas acerca das visões sobre corrupção e transferência de votos entre candidatos do primeiro para o segundo turno nos ajudam a entender o efeito da variável corrupção. Em primeiro lugar, a maior parte dos eleitores de Heloísa Helena e Cristóvam identificava a corrupção como um problema nacional. 90\% dos eleitores de Cristóvam e 59\% dos eleitores de Heloísa Helena se preocupavam com a corrupção. Dentre os quatro principais candidatos, esses são os indicadores mais altos. Cabe destacar que $46 \%$ dos eleitores de Lula e $52 \%$ dos eleitores de Alckmin no primeiro turno achavam que a corrupção era um problema nacional. Ou seja, a diferença entre os eleitores de Lula e Alckmin quanto a esse aspecto não era muito grande no primeiro turno da eleição.

Pois bem, dos eleitores que votaram em Heloísa Helena e Cristóvam no primeiro turno, $56 \%$ e $11 \%$, respectivamente, passaram a votar em Lula no segundo turno. $7 \%$ dos eleitores de Alckmin no primeiro turno decidiram mudar seu voto para Lula no segundo turno. Isso ajuda a entender, também, por que a votação total de Alckmin foi menor no segundo turno do que no primeiro. Dentre os eleitores de Heloísa Helena no primeiro turno que votaram em Lula no segundo turno, $68 \%$ indicaram a corrupção como problema. Já os de Cristóvam que pensavam que a corrupção era um problema migraram, na sua maioria esmagadora, para Alckmin. Contudo, o número absoluto desses casos foi menor do que o de Heloísa Helena. Se somarmos a isso os eleitores de Alckmin que mudaram de voto no segundo turno fica mais fácil entender o efeito positivo das visões sobre corrupção no voto em Lula no segundo turno.

De qualquer forma, a magnitude do efeito dessa variável, comparando os coeficientes, indica um impacto menor do que outras explicações para o voto. Como todas as variáveis são dummies, e contêm a mesma métrica, essa comparação é possível. Fica claro, portanto, que, na escolha entre Lula e Alckmin, prevaleceram fatores como visões sobre a economia, avaliação do governo Lula e algum componente partidário. 


\section{Conclusão e Implicações}

A análise dos dois turnos nos permite oferecer uma resposta ao enigma das eleições de 2006: como um governo envolvido em tantos escândalos de corrupção foi reeleito? No primeiro turno, a corrupção afetou o voto de uma porção pequena do eleitorado. Apenas a escolha entre Lula e Cristóvam foi claramente influenciada por esse fator, com o voto em Heloísa Helena sofrendo impacto menor. No que tange à principal disputa do primeiro turno, entre Lula e Alckmin, visões sobre a corrupção não tiveram qualquer efeito.

Já no segundo turno, eleitores que viam a corrupção como problema passaram a apoiar Lula. Contudo, tanto no primeiro quanto no segundo turnos, o desempenho do governo Lula em outras áreas e sentimentos quanto ao PT foram mais importantes e serviram de escudos para protegê-lo das acusações de corrupção, confirmando as hipóteses deste artigo.

O que esses achados podem nos dizer sobre a questão da "contabilidade democrática" vertical no Brasil? Contabilidade democrática vertical diz respeito à capacidade que o eleitor tem de punir os representantes que não correspondem às suas expectativas. Portanto, está relacionada a um voto retrospectivo. Contudo, a avaliação retrospectiva é multidimensional, pode estar relacionada ao desempenho da economia, a comportamento ético ou a outros fatores. Além disso, a escolha eleitoral leva em consideração outros cálculos, como identificação partidária e ideologia.

Claramente, os escândalos de corrupção não foram suficientes para levar Lula à derrota. Possíveis lealdades de mais longo prazo, como visões sobre os partidos políticos, além de avaliações retrospectivas e visões sobre a economia tiveram maior importância. Portanto, houve voto retrospectivo, só que mais fortemente influenciado por fatores clássicos, como visões sobre a economia ou avaliações gerais do governo.

Uma pergunta que fica ainda sem resposta, e que os dados utilizados aqui não permitem responder, é se os eleitores não se importam com corrupção quando há uma divisão ideológica clara entre candidatos ou se a retórica da candidatura de Lula teve muito êxito em se justificar perante as acusações de corrupção. Se Lula conseguiu se justificar perante os eleitores, isso garante algum tipo de representatividade e prestação de contas (STOKES, 2001; PITKIN, 1967).

Os escândalos de corrupção não apontaram culpa direta do candidato Lula, mas eram, sim, indicações de que seu governo estaria envolvido em casos de corrupção. Como tudo se colocou no condicional, houve margem ao acusado para alegações de inocência e de perseguição. Foi exatamente isso que Lula fez. Os eleitores podem acreditar na defesa do candidato, o que resulta em voto, ainda mais quando as acusações partem de tradicionais adversários políticos. Nesse sentido, a dúvida sobre a veracidade das acusações parece reduzir o impacto dos 
RENNÓ, L. R. Escândalos e voto: as eleições presidenciais brasileiras de 2006.

escândalos, indicando que outros fatores eleitorais são mais importantes, como a posição ideológica do partido ou coligação do candidato e a identificação partidária do eleitor. Mas, como foi dito, nossos dados sobre 2006 não permitem distinguir entre os dois fatores: não podemos afirmar com certeza que a retórica da defesa de Lula foi o que salvou sua reeleição. Os indícios são de que isso ocorreu, mas outros estudos são necessários para testar essa hipótese.

O que podemos afirmar a partir dos dados é que os escândalos não foram indicadores suficientemente fortes para levar à punição eleitoral na escolha que ocorreu entre dois candidatos de campos opostos na disputa política brasileira. Outras dimensões do voto retrospectivo e visões sobre partidos foram mais importantes.

\section{Referências Bibliográficas}

ALMEIDA, A. "A Esquerda dos Números à Direita dos Fatos." Insight Inteligencia, vol.15, p.112-128, 2001.

AMES, B.; BAKER, A.; MOCHEL, M. and RENNÓ, L. "Party Identification in Third Wave Democracies: Brazil's 2002 Elections." Prepared for delivery in the 2006 meeting of the Midwest Political Science Association, Chicago, 20-23 Apr., 2006.

CAMPBELL, A. et al. The American Voter. New York: Wiley Publishing, 1960.

CARREIRÃO, Y. A Decisão de Voto nas Eleições Presidenciais Brasileiras. Rio de Janeiro: Editora da FGV, 2002.

2007. "Relevant Factors for the Voting Decision in the 2002 Presidential Elections: An Analysis of the ESEB (Brazilian Electoral Studies) Data". Brazilian Political Science Review, 1:1, p.70:101, 2007.

CARREIRÃO, Y. e BARBETTA, P. A. "A Eleição Presidencial de 2002: A Decisão de Voto na Região da Grande São Paulo." Revista Brasileira de Ciencias Sociais vol.19, n.56, p.56-79, 2004.

CARREIRÃO, Y. e KINZO, M. D. "Partidos Políticos, Preferência Partidária e Decisão Eleitoral no Brasil (1989/2002)." Dados, vol.47, n.1, p.31-167, 2004. 
CONVERSE, P. The Concept of the Normal Vote. In CAMPBELL et al., Elections and the Political Order. New York: Wiley, 1966.

DELLI CARPINI, M. X. and KEETER, S. What Americans Know About Politics And Why It Matters. New Haven: Yale University Press, 1996.

FELDMAN, S. e ZALLER, J. "The Political Culture of Ambivalence: Ideological Responses to the Welfare State." American Journal of Political Science, vol.36, p.268-307, 1992.

FIORINA, M. Retrospective Voting in American National Elections. New Haven: Yale University Press, 1981.

GREEN, D. and PALMQUIST, B. "How stable is party identification?" Political Behavior, vol.16, p.437.466, 1994.

HOLBROOK, T. "Campaigns, National Conditions, and U.S. Presidential Elections." American Journal of Political Science, vol.38, p.973-98, 1994.

KINDER, R. e KIEWIT, D. "Sociotropic Politics: The American Case." British Journal of Political Science, vol.11, p.129.61, 1981.

KING, G., KEOHANE, R. O., VERBA, S. Designing Social Inquiry: Scientific Inference in Quantitative Research. Princeton: Princeton University Press, 1994.

LUPIA, A. "Shortcuts Versus Encyclopedias: Information and Voting Behavior in California Insurance Reform Elections." American Political Science Review, vol.88, n.1, p.63-76, 1994.

LUSKIN, R. From Denial to Extenuation (and Finally Beyond): Political Sophistication and Citizen Peformance. In: KUKLINSKI, J. (ed.) Thinking About Political Psychology. Cambridge: Cambridge University Press, 2002.

MAINWARING, S. P. and SCULLY, T. (eds.). Building Democratic Institutions: Party Systems in Latin America. Stanford: Stanford University Press, 1995.

MENEGUELLO, R. Partidos e Tendências de Comportamento: O Cenário Político em 1994. In: DAGNINO, E. (ed.). Os Anos 90: política e sociedade no Brasil. São Paulo: Brasiliense, p.151. $171,1994$.

NICOLAU, J. "An Analysis of the 2002 Presidential Election using Logistic Regression." Brazilian Political Science Review, vol.1, n.1, p.125-135, 2007. 
RENNÓ, L. R. Escândalos e voto: as eleições presidenciais brasileiras de 2006.

O'DONNELL, G. “Delegative Democracy”. Working Paper Series, The Helen Kellogg Institute for International Studies, 1994.

PAPPI, F. U. "Political Behavior: Reasoning Voters and Multi-party Systems." In: GOODIN, R. and KLINGEMANN, H. (eds.). A New Handbook of Political Science. Oxford: Oxford University Press, p.255-275, 1996.

PEREZ-LIÑAN, A. Presidential Impeachment and the New Political Instability in Latin America. Cambridge: Cambridge University Press, 2007.

PITKIN, H. The Concept of Representation. Berkeley: University of California Press, 1967.

PRZEWORSKI, A., STOKES, S. and MANIN, B. Democracy, Accountability, and Representation. Cambridge: Cambridge University Press, 1999.

RENNÓ, L. "Notes on the 2006 Brazilian Presidential Elections: The Winding Road to Democratic Consolidation." Colombia Internacional, vol.64, p.154-165, 2006.

RENNÓ, L. e SPANAKOS, A. "Macroeconomia, Mercado Financeiro e Intenção de Voto para presidente: As Eleições Brasileiras de 1994, 1998 e 2002." Dados-Revista De Ciências Sociais, vol.49, n०.1, 2006.

SAMUELS, D. "Sources of Mass Partisanship in Brazil." Latin American Politics and Society, vol.48, n.2, p.1-27, 2006.

SINGER, A. Esquerda e Direita no Eleitorado Brasileiro: A Identificação Ideológica nas Disputas Presidenciais de 1989 e 1994. São Paulo: Edusp, 1999.

SNIDERMAN, P. "Taking Sides: A Fixed Choice Theory of Political Reasoning." In: LUPIA, A., MCCUBBINS, M. and POPKIN, S. (eds.). Elements of Reason: Cognition, Choice, and the Bounds of Rationality. Cambridge: Cambridge University Press, 2000.

STOKES, S. Public Support for Market Reforms in New Democracies. Cambridge: Cambridge University Press, 2001.

ZALLER, J. R. The Nature and Origins of Mass Opinion. Cambridge: Cambridge University Press, 1992. 
OPINIÃO PÚBLICA, Campinas, vol. 13, n², Novembro, 2007, p.260-282

\section{Anexo: Questões utilizadas- ESEB2006}

ESEB1) Qual assunto o(a) sr.(a) considera que foi o mais importante nesta eleição?

ESEB1a) E em segundo lugar?

ESEB2) Qual é o principal problema político do Brasil hoje?

ESEB2a) Em em segundo lugar?

ESEB11) De um modo geral, existe algum partido político que o(a) Sr(a) goste? (ESPONTÂNEA E ÚNICA)

ESEB12) Qual partido o(a) Sr(a) gosta? . (ESPONTÂNEA E MÚLTIPLA)

ESEB19) (MOSTRAR CARTÃO ESEB18) Novamente pensando em esquerda e direita na política. Como o(a) Sr(a) se considera? Zero significa que o(a) $\operatorname{Sr}(a)$ é de esquerda e 10 que o(a) Sr(a) é de direita. (ESTIMULADA E ÚNICA)

ESEB25) (MOSTRAR CARTÃO ESEB25) Em quem o(a) Sr(a) votou para presidente no primeiro turno, em Lula, Alckmin, Heloísa Helena, Cristóvam Buarque ou Luciano Bivar? (ESTIMULADA E ÚNICA) (INSTRUÇÃO: Alternar a ordem de leitura dos nomes dos candidatos a cada questionário aplicado)

ESEB27) E no segundo turno, o(a) sr(a) votou em Lula ou Alckmin?

ESEB43) (MOSTRAR CARTÃO ESEB) Em quais desses partidos políticos o(a) Sr(a) não votaria de jeito nenhum? (ESTIMULADA E MÚLTIPLA) (PERGUNTAR PARA CADA PARTIDO)

\begin{tabular}{|c|c|c|c|c|c|c|c|}
\hline & & Não votaria & Votaria & $\begin{array}{c}\text { Não conhece } \\
\text { o partido }\end{array}$ & NS & NR & NA \\
\hline a) & PT & 0 & 1 & 55 & 77 & 99 & 88 \\
\hline
\end{tabular}

ESEB58) Agora para finalizar, gostaria que o(a) sr(a) dissesse se as seguintes frases estão certas ou erradas:

\begin{tabular}{|l|c|c|c|c|}
\hline & CERTO & ERRADO & NS & NR \\
\hline 1) Geraldo Alckmin pertence ao PTB & 1 & 2 & 77 & 99 \\
\hline $\begin{array}{l}\text { 2) O presidente da república tem um } \\
\text { mandato de 4 anos }\end{array}$ & 1 & 2 & 77 & 99 \\
\hline $\begin{array}{l}\text { 3) Os deputados da Câmara Federal são } \\
\text { eleitos pelo voto majoritário }\end{array}$ & 1 & 2 & 77 & 99 \\
\hline 4) O presidente Lula foi eleito pelo PT & 1 & 2 & 77 & 99 \\
\hline
\end{tabular}

